\title{
EXPERIMENTAL AND SIMULATIVE STUDY ON ACCUMULATOR FUNCTION IN THE PROCESS OF WAVE ENERGY CONVERSION
}

\author{
Wei Zhang, Ph. D., \\ Yanjun Liu, Ph. D., \\ Huaqing Luo, \\ Gang Xue, Ph. D., \\ Jian Zhang, Ph. D., \\ Mechanical Engineering Institute, Shandong University, \\ Jinan, Shandong, China
}

\begin{abstract}
In this paper, a floating-buoy wave energy converter using hydrostatic transmission system is studied. The entire work progress of wave energy power generation device is introduced, and the hydraulic transmission principles are emphasized through the simulation to verify the feasibility of design principle of hydraulic transmission system. The mathematical model of the accumulator is established and applied in the AMEsim simulation. The simulation results show that the accumulator plays an important role in the wave power hydraulic transmission system and that the correct configuration of accumulator parameters can improve the rapidity and stability of the system work. Experimental results are compared with the simulation results to validate the correctness of the simulation results. This would provide a valuable reference to the optimal design of wave power generation.
\end{abstract}

Keywords: wave energy converter, AMESim simulation, accumulator, experimental verification

\section{INTRODUCTION}

With the development of science and technology, and the increase in the level of productivity, the human demand for energy grows daily thus causing the intense consumption of non-renewable energy, such as petroleum, natural gas and coal resources, and resources have become increasingly depleted[1]. Fossil energy consumption also caused a straight rise in carbon dioxide emissions. In order to ease the pressure on the energy crisis, it is imperative to carry out new energy research to develop and utilize clean energy [2]. It is urgent to establish an energy structure dominated by clean, renewable energy and gradually replace fossil fuel based energy structure. The utilization of renewable energy is related to human survival and the future of mankind [3]. Wave energy technology is a useful solution to solve energy and environmental issues. The hydraulic transmission is one of the important components [4].

Wave energy power generation technology is through the wave energy absorption and conversion device to convert the wave energy into electric energy [5]. Marine technology is becoming outdated, which shows a good prospect for the full use of the ocean in the new century. But so far, the use of it also faces many challenges. The output of the ocean energy generator is unstable, and the change of the wave can cause the mechanical power of the energy absorbing mechanism to change. The output power of the generator then fluctuates and the power quality is reduced. Therefore, the improvement of the stability of the output power quality of the generator has become an important problem in wave power generation 
technology [6].

Usage of the hydraulic drive system to replace the traditional mechanical transmission system can reduce the energy fluctuation caused by the irregular change of front end input [7]. The ability to control the hydraulic oil as the transmission medium is greater than gear boxes and other mechanical transmission device because it is a flexible medium, which easily realizes the stepless speed change to ensure generators to maintain in the vicinity of the synchronous speed to further improve the stability of power system.

At present, most wave energy converters use hydraulic energy transmission, so the hydraulic system has great promise in the research of wave energy converters [8]. A series of studies of hydraulic power take-off in different wave energy converter models have been conducted by Bjarte-Larsson and Falnes (2006) [9], Hals et al. (2007) [10], Yang et al. (2009) [11] and others. Yang, Hals and Moan [12] studied on a heavingbuoy wave energy converter equipped with a high-pressure hydraulic power take-off machine. The mathematical model was designed to investigate the wear damage in the hydraulic machine. Falcão[13]focused a study on oscillating-body wave energy converters with hydraulic power take-off and gas accumulator. The results show that the hydraulic system with accumulators can better transform the wave energy with a stable output power. However, there is no perfect solution to stabilize the output power [14], and the comparison analysis of semi-physical experiment to simulation results is not fully expressed.

In this paper, study on the output pressure and voltage characteristics of power generation system and the response characteristics and stability of the energy conversion system with the effect of the accumulator. The first section introduces the working principle and the hydraulic transmission system of wave energy converter. The second section describes the construction of the AMESim simulation model based on the design principle, the simulation parameters are established by the theoretical calculation, and the simulation results show that the hydraulic system with accumulator can make the output power stable [15].

In the third section, according to the simulation analysis results, the semi-physical experiments are carried out and

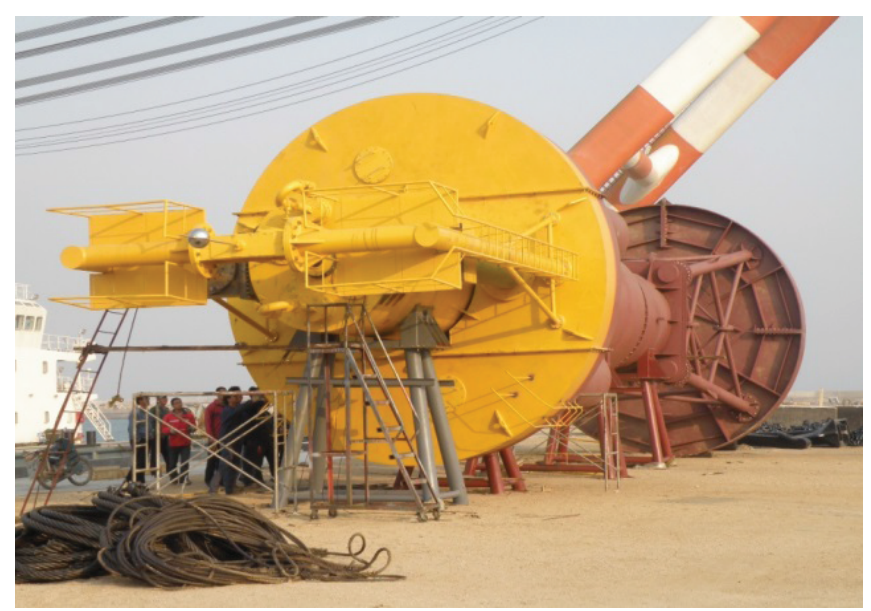

Fig. 1. Wave energy power generation device compared with the simulation results. This paper further demonstrates that the accumulator can improve the power output characteristics of the machine greatly, and the correct configuration parameter of storage can improve the stability and rapidity of output energy [16].

Fig. 1 is the new type of wave energy power generation device. The device adopts the hydraulic transmission system, which can convert the unstable wave energy into a stable power output. This paper takes the hydraulic conversion system as the research object, which is the core technology used in the wave energy power generation system.

\section{WORK PRINCIPLE AND COMPOSITION OF WAVE ENERGY CONVERTER}

The whole wave energy generating device is composed of a wave energy collection system, hydraulic transmission system, energy storage system, power output and data acquisition system. Fig. 2 is the schematic diagram of floating wave power generation device.

The wave energy collection system can convert the wave energy into mechanical energy of float. The movement of float can convert the mechanical energy to hydraulic energy, which travels through the hydraulic system and drives the motor to rotate, thus driving the generator to work and output power stably.

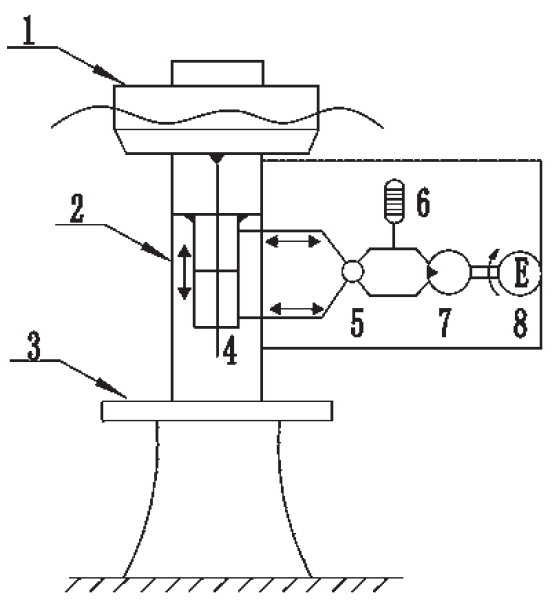

Fig. 2. Intention picture of wave power generation system. 1. float 2. buoy 3 . damping plate 4. hydraulic cylinder 5. regulating valves 6. accumulator 7 . motor 8. generator

\section{HYDRAULIC TRANSMISSION PRINCIPLE}

The hydraulic drive system is the most important part in ensuring the output power of device, which can buffer the impact of the irregular wave energy. Fig. 3 is the working principle diagram of the hydraulic transmission system through the hydraulic cylinder of double rod to improve the output efficiency of hydraulic transmission system. It can ensure that the hydraulic energy discharges continuously whether the float movement is upward or downward. The hydraulic rectification module is composed of the one-way valve to ensure that the hydraulic output is in the same direction, so that the motor rotates in the same direction always. By matching 
the parameters of each part of the hydraulic drive system reasonably can guarantee the output power more stable.

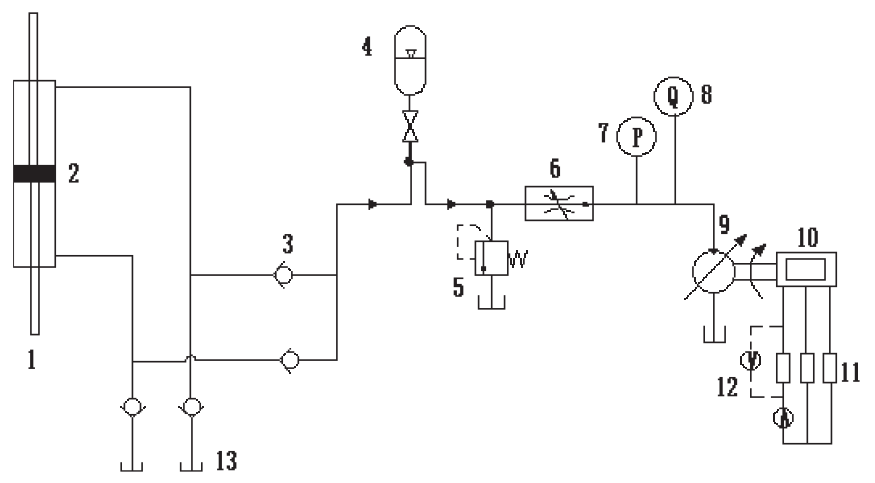

Fig. 3. Working principle of hydraulic transmission system. . hydraulic rod 2. hydraulic cylinder 3. one-way valve 4. accumulator 5. relief valve 6. speed regulation valve 7. pressure sensor 8 . flow sensor 9. motor 10 . generator 11 .load 12. voltage sensor 13. oil tank

\section{SIMULATION AND ANALYSIS}

\section{THE ESTABLISHMENT OF MODEL}

Fig. 4 is the simulation model established using AMESim software according to the working principle of the hydraulic transmission system. By setting the amplitude and period of the input signal, movement state of float under different wave conditions can be analogized.

Fig. 4. Simulation model

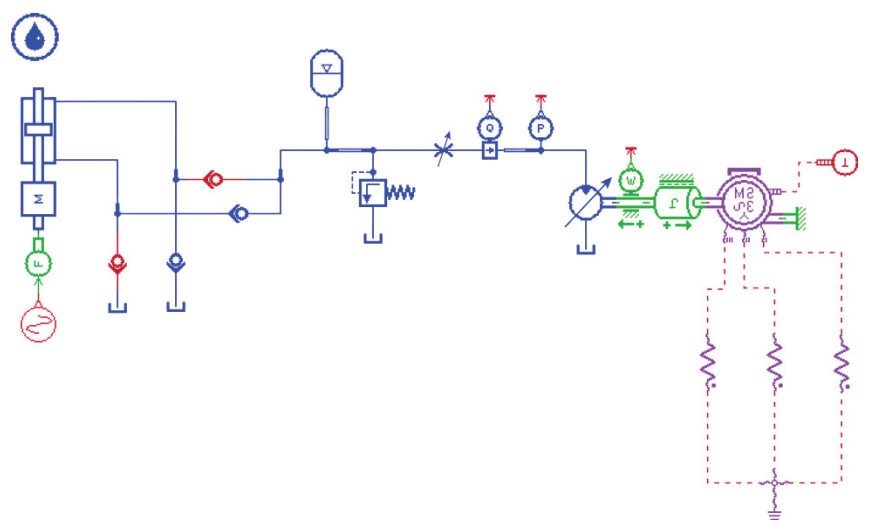

The main parameters of the model are set up as shown in Tab. 1:

Tab. 1. Main parameters of the model

\begin{tabular}{|c|c|}
\hline Main model & Settings parameters \\
\hline $\begin{array}{l}\text { The total weight of the Moving } \\
\text { part of float }\end{array}$ & $15000 \mathrm{~kg}$ \\
\hline Piston diameter & $180 \mathrm{~mm}$ \\
\hline Diameter of piston pole & $140 \mathrm{~mm}$ \\
\hline Hydraulic cylinder stroke & $5 \mathrm{~m}$ \\
\hline Hydraulic motor & $\begin{array}{l}\text { speed: } 1000 \mathrm{rev} / \mathrm{min} \text {; displacement: } \\
160 \mathrm{~mL} / \mathrm{r}\end{array}$ \\
\hline Electrical generators & $\begin{array}{l}\text { three-phase permanent synchronous } \\
\text { generators }\end{array}$ \\
\hline
\end{tabular}

\section{VALIDATION OF SIMULATION MODEL}

The simulation system is operated to verify whether the built simulation model is correct. Fig. 5 is the error contrast between the actual motion curve and the desired curve.

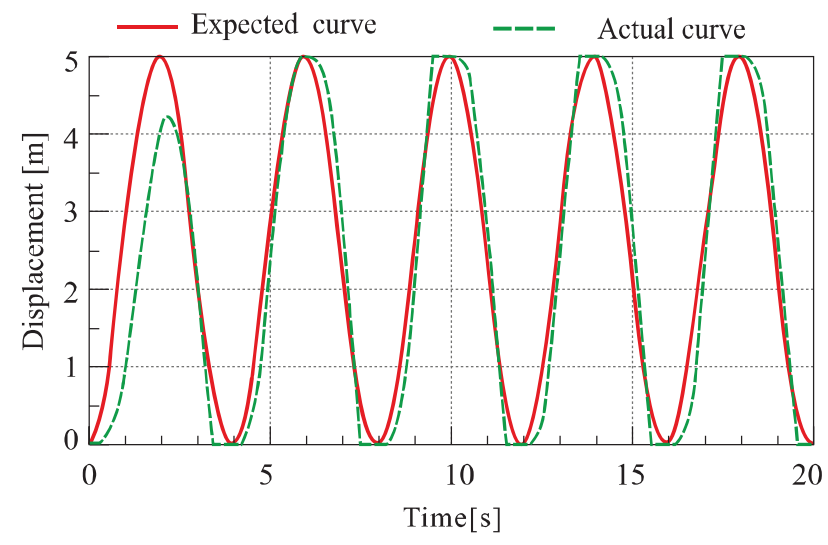

Fig. 5. Contrast displacement curve of float and the expected value

Fig. 5 suggests when the system started to run the oil pressure was not established, so the displacement of float is not demonstrated in the target displacement. After one cycle, the float displacement curve is in conformity with the expectation curve. It executes the sinusoidal movement according to the amplitude of $5 \mathrm{~m}$ cycle $4 \mathrm{~s}$ schedules. The trajectories of float in the allowable error range that verifies the establishment of the simulation model is correct and can be used to further explore the role of each part of the hydraulic system and study the effect of different parameters on the system output stability and velocity.

\section{THE SIMULATION ANALYSIS OF ACCUMULATOR}

The accumulator has the effect of peak clipping and valley filling in hydraulic transmission systems, and it can cushion the impact of irregular wave energy, as well as guarantee the stability of hydraulic transmission. It plays a key role in stabilizing the output power of the system [17].First, to explore the working state effect of the accumulator parameters for the system, a mathematic model of the accumulator is built, and the bottom area of wallet is $A_{a}$. The quality of the oil into the oil chamber is $m_{a}$. Ignore the elastic modulus of hydraulic oil the force analysis equation of hydraulic oil in the oil chamber is [18]:

$$
\left(p-p_{a}\right) A_{a}=\frac{m_{a} \frac{d^{2} V_{a}}{d t^{2}}+B_{b} \frac{d V_{a}}{d t}+C_{a} \frac{d V_{a}}{d t}+\mathrm{k}_{a} V_{a}}{A_{a}}
$$

In Eq. (1):

$p$ - Oil cavity pressure near the oil outlet end;

$P_{a}$ - Chamber pressure;

$B_{b}$ - The damping coefficient of oil cavity;

$\mathrm{k}_{a}$ - The spring stiffness of the gas;

$C_{a}$ - The damping coefficient of the gas;

$V_{a}$ - Accumulator volume. 
Assuming $\left(P_{1}, V_{1}\right)$ is pressure and volume state of a certain working point, $\left(P_{a}, V_{a}\right)$ is the working state of the accumulator on any point in a chamber, by the gas formula one can get:

$$
P_{1} V_{1}^{k}=P_{a} V_{a}^{k}
$$

By applying derivation to point $\left(P_{1}, V_{1}\right)$ in Eq. 2 and omitting the higher order terms one can get:

$$
\frac{d P_{a}}{d t}=-\frac{d P_{1}}{V_{1}} \cdot \frac{d V_{a}}{d t}
$$

The hydraulic oil flow rate of accumulator inlet valve is:

$$
q_{4}=-\frac{d V_{a}}{d t}
$$

Combine Eq. 3 and 4 one obtain:

$$
P_{a}=\frac{k P_{a 0}}{V_{a 0}} q_{4} .
$$

Replace $q_{4}$ in Eq. 5 using Eq. 4, then substitute into Eq. 1 to form the Laplace transform:

$$
G(s)=\frac{P_{a}(s)}{Q_{4}(s)}=\frac{1}{A_{a}{ }^{2}} \cdot \frac{1}{s}\left[m_{a} s^{2}+\left(B_{b}+C_{a}\right) s+\left(\mathrm{k}_{a}+\frac{k P_{a 0} A_{a}^{2}}{V_{a 0}}\right)\right]
$$

If the flow of accumulator inlet valve is $q$, the oil cavity fluid changes and storage volume change can be calculated from Eq. (7):

$$
q=-\frac{\Delta V}{\Delta t}
$$

Then:

$$
q=-\dot{V}_{a}
$$

After making Eq. (8) Laplace transformation then brings into Eq. (6) one can obtain the mathematical model of accumulator by gas chamber volume as the output:

$$
G(s)=\frac{V_{a}(s)}{P_{a}(s)}=\frac{A_{a}{ }^{2}}{m_{a} s^{2}+\left(B_{b}+C_{a}\right) s+\left(\mathrm{k}_{a}+\frac{k P_{a 0} A_{a}{ }^{2}}{V_{a 0}}\right)}
$$

Then one can get:

$$
G(s)=\frac{A_{a}{ }^{2}}{\left(\mathrm{k}_{a}+\frac{k P_{a 0} A_{a}{ }^{2}}{V_{a 0}}\right)} \cdot \frac{\omega_{n}{ }^{2}}{s^{2}+2 \zeta \omega_{n} s+\omega_{n}{ }^{2}}
$$

where $\omega_{n}$ is the undamped natural frequency of accumulator, $\zeta$ is the gas - oil equivalent damping ratio of accumulator. We can see that the performance of the hydraulic accumulator is associated with the cross section area of circle, air pressure, and air volume [19].

In order to further explore what role the accumulator plays in the wave power hydraulic transmission system and the influence of its main parameters on the stability and rapidity of the system, we carry out the concrete analysis through the AMESim simulation model [20].

When the gas pressure of the accumulator is $10 \mathrm{MPa}$, the gas volume is $40 \mathrm{~L}$ then run the simulation model. Fig. 6 is the motor outlet pressure simulation curves when the accumulator is open and closed.

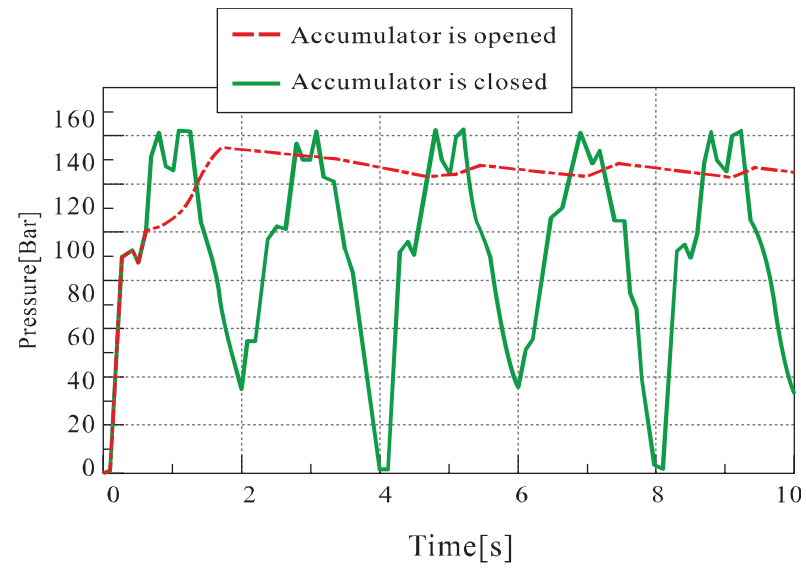

Fig. 6. Outlet pressure curve of motor when accumulator is open or closed

Fig. 6 suggests when the accumulator is open, the establishing time of motor output port pressure is $1.8 \mathrm{~s}$, the peak pressure is $13 \mathrm{MPa}$. After $5 \mathrm{~s}$ the output pressure stabilized at about 12 $\mathrm{MPa}$, the output pressure of the motor is relatively stable, thus ensuring the stability of synchronous generator output power.

When the accumulator is turned off, the system pressure is created after $0.8 \mathrm{~s}$ and the peak pressure is $14 \mathrm{MPa}$, then the oil pressure continued to decrease rapidly and reduced to $3.9 \mathrm{MPa}$ at $2 \mathrm{~s}$, when the time is $3.5 \mathrm{~s}$ the pressure is raised to $14 \mathrm{MPa}$ again, and at $4 \mathrm{~s}$ the pressure will be zero, this process cycle is a continuous operation. The maximum pressure fluctuation difference is $14 \mathrm{MPa}$, the output pressure is not stable, and it will cause difficulty to the subsequent power handling progress.

Through comparative analysis of simulation curves one can get the accumulator can absorb the impact pressure in the system effectively and keep the pressure of hydraulic system stable. It plays an obvious role in hydraulic transmission systems. But the existence of the accumulator also reduces the system response speed and decreases the peak. Therefore, the reasonable matching of accumulator parameters to improve the rapidity and stability of the system is the key of the study. The air pressure and air volume is the main parameters of accumulator. Next, we will make the specific analysis about their influence on the work state of system.

\section{PRESSURE OF ACCUMULATOR INFLUENCE ON THE SYSTEM}

The volume of the accumulator is set at $40 \mathrm{~L}$, and the working pressure is $8,10,11,13 \mathrm{MPa}$, respectively. The output pressure curve of motor is shown in Fig. 7 after running the simulation model. 


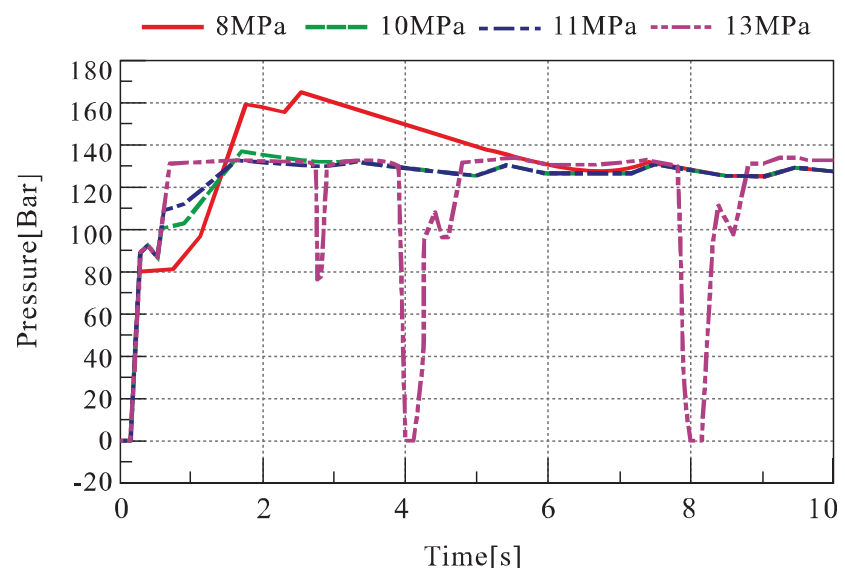

Fig. 7. Outlet pressure curve of motor when accumulator with different storage pressure

Fig. 7 suggests when the inflation pressure of accumulator is too small at $8 \mathrm{MPa}$, the peak pressure of motor is greater than $17 \mathrm{MPa}$, and the response time is $3 \mathrm{~s}$. When the air pressure in accumulator is $13 \mathrm{MPa}$, the response time of system is $0.8 \mathrm{~s}$, but the impact pressure is shocked evidently. When the pressure of accumulator is $10 \mathrm{MPa}$ or $11 \mathrm{MPa}$, the response time is $1.8 \mathrm{~s}$ and the output pressure of system is relatively stable, remaining at about $12.4 \mathrm{MPa}$. The simulation results show that when the filling pressure is $80 \%$ or $90 \%$ of the actual working pressure, the rapidity and stability of system output is better.

\section{VOLUME OF ACCUMULATOR INFLUENCE ON THE SYSTEM}

The setting of the accumulator pressure is $10 \mathrm{MPa}$ and the inflatable volume is 10,20 , and $40,60 \mathrm{~L}$, respectively. Fig. 8 shows the output pressure curve after running the simulation model.

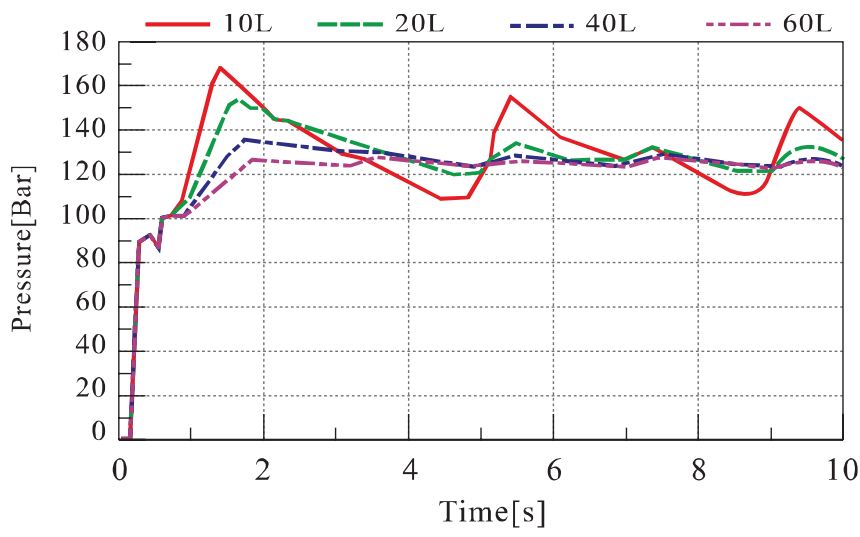

Fig. 8. Outlet pressure curve of motor when accumulator with different volume

Fig. 8 suggests when the charging volume of accumulator is $10 \mathrm{~L}$ or $20 \mathrm{~L}$; the response time is $1.5 \mathrm{~s}$ and $1.7 \mathrm{~s}$, respectively. The peak pressure of system is $7 \mathrm{MPa}$ and $15 \mathrm{MPa}$. When the charging volume of accumulator is $60 \mathrm{~L}$, the peak pressure is 12.7 $\mathrm{MPa}$, then the buffer effect for system is obvious, but the response time becomes slower for $2 \mathrm{~s}$. When the gas volume is $40 \mathrm{~L}$, the buffer effect for system is medium and the maximum pressure is $13.2 \mathrm{MPa}$, the response time is $1.8 \mathrm{~s}$. The simulation results show: when accumulator aeration volume is too small, the buffer effect is reduced, the pressure output volatility is obvious; if the inflatable volume is too large the system response will become slow, the cost will increase and the occupied space becomes large.

\section{EXPERIMENTAL RESULT AND ANALYSIS}

\section{CONSTRUCTION OF EXPERIMENTAL APPARATUS}

For experimental study of the performance of each component and how the settings parameter will bring the influence on the work state of system, setup of the land test bench is shown in Fig. 9: Using the hoist to pull the float along with the buoy moves up and down to simulate the movement of float which acted on by the vertical wave forces. Then the hydraulic energy can be transferred and the system could output power finally.

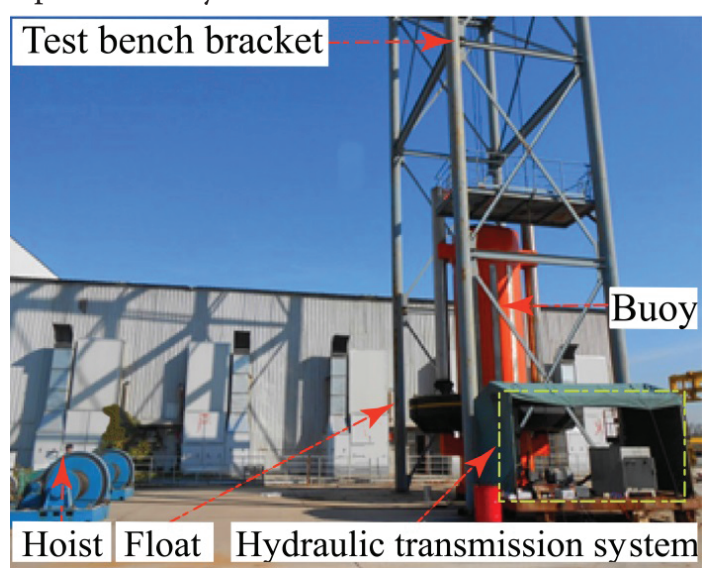

Fig. 9. Experimental apparatus

Fig. 10 is the main part of hydraulic transmission system and data acquisition system, the PC software can collect the real-time data of float displacement, the outlet pressure of motor, the output voltage, and the current parameters of generator. It provides the reference for further analysis and design optimization of the system.

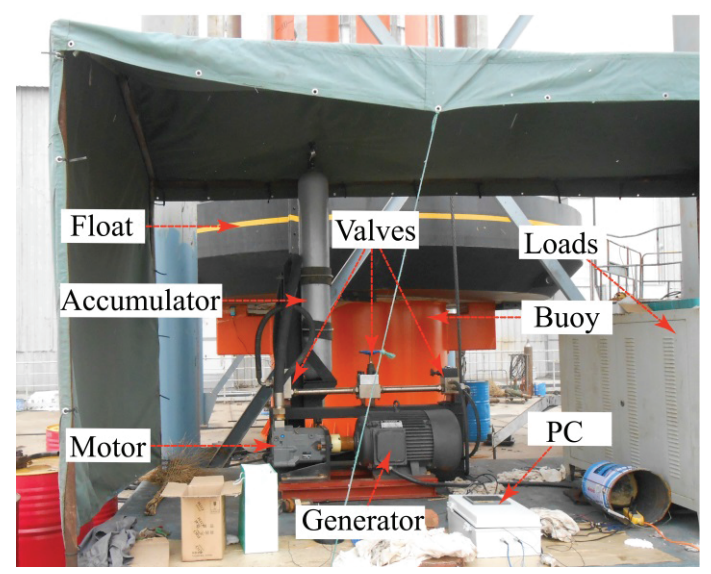

Fig. 10. Hydraulic transmission system and data collecting system 


\section{EXPERIMENTAL DATE ANALYSIS}

Fig. 11 is the motor pressure curve and output voltage curve of the generator when the accumulator volume is $40 \mathrm{~L}$ and the pressure is $10 \mathrm{MPa}$. After $5 \mathrm{~s}$ of float running, the motor output pressure gradually built up, and the maximum peak pressure reached $11.7 \mathrm{MPa}$, the pressure fluctuation ranges from 8.8 to $11.7 \mathrm{MPa}$. The generator output voltage peak value is $240 \mathrm{~V}$, and the voltage fluctuation ranges from 180 to 240 $\mathrm{V}$. The change trend of voltage output curve is consistent with the change trend of motor output pressure curve.

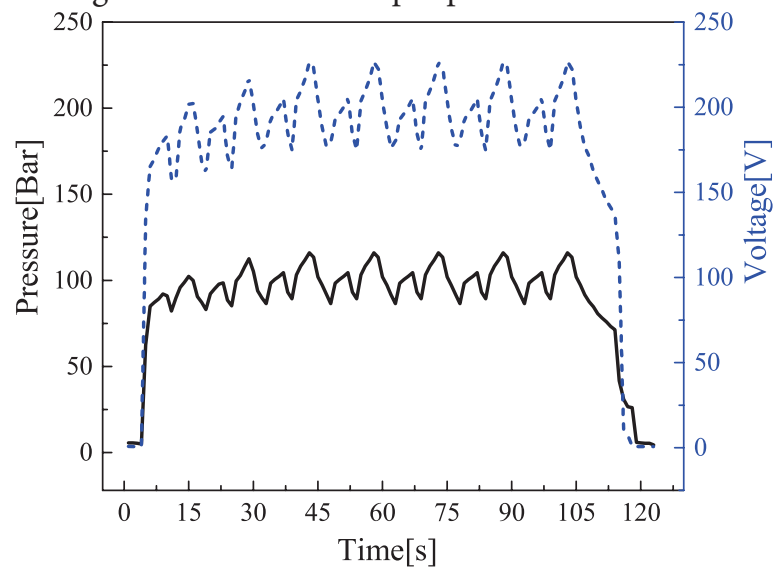

Fig. 11. Motor pressure and generator voltage curves

Fig. 12 is the motor output pressure and generator output voltage curve when the accumulator is turned off. In this case, the fluctuations of output pressure and voltage curves are obvious and its value is discontinuous. The maximum pressure difference is $14 \mathrm{MPa}$, and the maximum voltage difference is 300 $\mathrm{V}$. The output peak is greater than the condition of accumulator is open; it is identical with the simulation results. When the accumulator is closed, after the float stopping movement, the generator can continue to run $1 \mathrm{~s}$ under the force of inertia then stopped immediately. When the accumulator is open, after the float stopping movement, the generator will still continue to generate electricity for about $10 \mathrm{~s}$, thus ensure the continuity of electricity output.

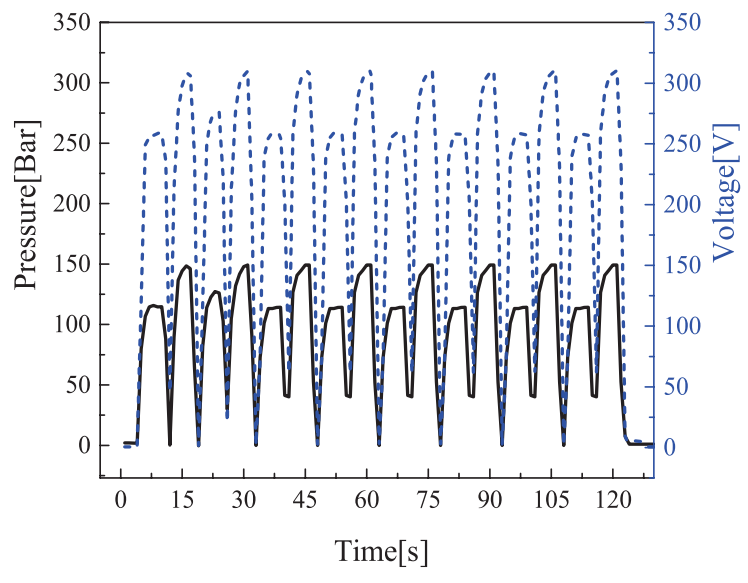

Fig. 12. Motor pressure and generator voltage curves

Fig. 13 is the pressure and voltage curves when the volume of accumulator is $40 \mathrm{~L}$ and the pressure is $5 \mathrm{MPa}$. When the float has been running for $6 \mathrm{~s}$, the output pressure of motor is gradually built up, then the maximum pressure peak is 12.5 $\mathrm{MPa}$ and the pressure fluctuation ranges from 9.5 to $12.5 \mathrm{MPa}$. The generator output voltage peak value is $210 \mathrm{~V}$, the voltage fluctuation ranges from 160 to $210 \mathrm{~V}$. For comparison, the pressures and voltage output curves under the condition of same air volume and different air pressure is analyzed. It can be drawn: when the air pressure in the accumulator is smaller, the output peak of pressure is larger, the voltage fluctuation range becomes smaller, and when the float stops motion the generator can output power continuously for a longer time.

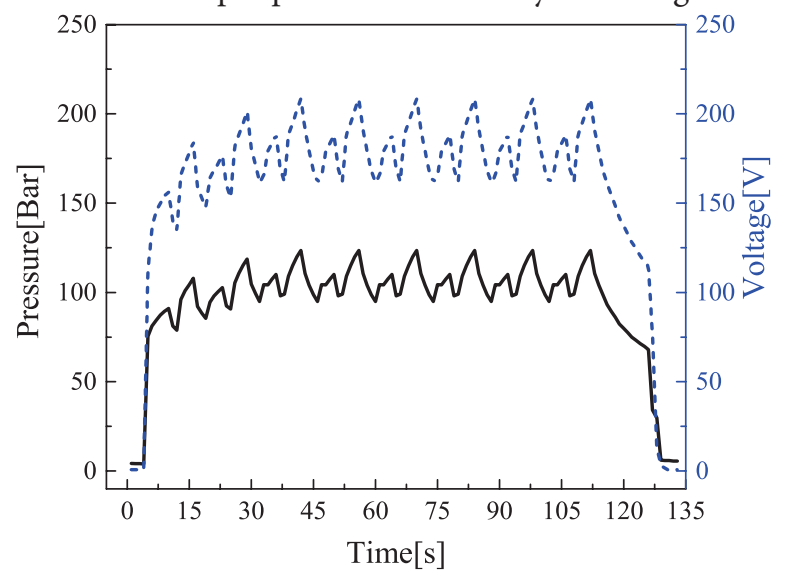

Fig. 13. Motor pressure and generator voltage curves

\section{CONCLUSIONS}

1. The changing trends of experimental data curves and simulation curves are consistent, verifying that the design principle of hydraulic drive system is feasible and the built of simulation model is correct. The study on the hydraulic transmission systems of wave energy converter clarifies the impact of accumulator on the power production. It provides a reliable reference for further optimization.

2. By analyzing the simulation curves and experimental data curves one can obtain that the accumulator plays an enormous role in relieving the pressure impact of system and the correct configuration of accumulator parameters can improve the rapidity and stability of the system work.

\section{ACKNOWLEDGEMENTS}

This project is partially supported by Renewable Energy Special Foundation of China Oceanic Administration (GHME2010ZC01), Renewable Energy Special Foundation of China Oceanic Administration (SDME2010GC02) and Shandong University Oriented Project "Research on Key Scientific Problems of Marine Resources and the Use (2014QY006)". 


\section{BIBLIOGRAPHY}

1. Wang, S.j., Yuan, P., Li, D., Jiao, Y.H.: An overview of ocean renewable energy in China, Renew Sustain Energy Rev, Vol. 15, no. 1, pp. 91-111, 2011.

2. Falnes, J.: A review of wave-energy extraction, Mar. Struct, Vol. 20, no. 4, pp. 185-201.

3. Bahaj, A.B.S.: Generating electricity from the oceans, Renewable and Sustainable Energy Reviews, Vol. 15, no. 7, pp. 3399-3416, 2011.

4. López, I., Andreu, J., Ceballos, S., Alegría, I.M.D., Kortabarria, I.: Review of wave energy technologies and the necessary power-equipment, Renewable and Sustainable Energy Reviews, Vol. 27, no. 6, pp. 413-434, 2013.

5. Coiro, D.P., Troise, G., Calise, G., Bizzarrini, N.: Wave energy conversion through a point pivoted absorber: Numerical and experimental tests on a scaled model, Renewable Energy, Vol. 87, no. 1, pp. 317-325, 2016.

6. Martínez, M., Molina, M.G., Machado, I.R.: Mercado, P.E., Watanabe, E.H., Modelling and simulation of wave energy hyperbaric converter (WEHC) for applications in distributed generation, International Journal of Hydrogen Energy, Vol. 37, no. 9, pp. 14945-14950, 2012.

7. Gaspar, J.F., Calvário, M., Kamarlouei, M., Guedes Soares, C.: Power take-off concept for wave energy converters based on oil-hydraulic transformer units, Renewable Energy, no. 86, pp. 1232-1246, 2016.

8. Zhang, D.H., Li, W., Lin Y.G.: Wave energy in China: current status and perspectives, Renewable energy, Vol. 34, no. 10, pp. 2089-2092, 2009.

9. Bjarte-Larsson, T., Falnes, J.: Laboratory experiment on heaving body with hydraulic power take-off and latching control, Ocean Eng, Vol. 33, no. 7, pp. 847-877, 2006.

10. Hals, J., Taghipour, R., Moan, and T.: Dynamics of a force-compensated two-body wave energy converter in heave with hydraulic power take-off subject to phase control, In: Proceedings of the Seventh European Wave and Tidal Energy Conference, Porto, Portugal, 2007.

11. Yang, L.M., Hals, J., Moan, T.: A wear model for assessing the reliability of wave energy converter in heave with hydraulic power take-off, In: Proceedings of the Eighth European Wave and Tidal Energy Conference, Uppsala, Sweden, 2009.

12. Yang, L., Hals, J., Moan, T.: Analysis of dynamic effects relevant for the wear damage in hydraulic machines for wave energy conversion, Ocean Engineering. Vol. 37, no, 13, pp. 1089-1102, 2010.

13. Falcão, A. F. de O.: Modelling and control of oscillating-body wave energy converters with hydraulic power take-off and gas accumulator, Ocean Engineering, Vol. 34, no. 14-15, pp. 2021-2032, 2007.

14. Virvalo, T.: Hydraulic systems in wave energy application, 1st edn, World Publishing Corporation, China, pp. 56-60, 2009.

15. Lin, Y, G., and Huang, W., Zhang, D.F., Li, W., Bao, J.W.: Application of Hydraulic System in Wave Energy Converter, Electrical, Information Engineering and Mechatronics
2011, Lecture Notes in Electrical Engineering. Vol. 138, pp. 275-283, 2012.

16. Lopes, M.F.P., Hals, J., Gomes, R.P.F., Moan, T., Gato, L.M.C., Falcão, A.F.de O.: Experimental and numerical investigation of non-predictive phase-control strategies for a point-absorbing wave energy converter, Ocean Engineering, Vol. 36, no. 5, pp. 386-402, 2009.

17. Babarit, A., Guglielmi, M., Clément, A.H.: Declutching control of a wave energy converter, Ocean Engineering, Vol. 36, no. 12-13, pp. 1015-1024, 2009.

18. Zhan, X.Q., Zhang, Y.H., Zhao, K.D.: Study on Mathematical Model of Hydraulic Accumulator in Secondary Regulated System, China Mechanical Engineering, Vol. 12, no. Zl, pp. 45-46, 2001.

19. Quan, L.X., Kong, X.D., GAO, Y.J., Kang, S.Q., Yao, and J.: Theory and experiment of accumulator absorbing pressure pulsation without regard to its entrance characteristics, Chinese Journal of Mechanical Engineering, Vol. 43, no. 9, pp. 28-32, 2007.

20. Wang, C.W., Jiao, Z.X., Wu, S., Shang, Y.X.: An experimental study of the dual-loop control of electro-hydraulic load simulator, Chinese Journal of Aeronautics, Vol. 26, no. 6, pp. 1586-1595, 2013.

\section{CONTACT WITH THE AUTHOR}

Yanjun Liu, Ph.D.

e-mail:lyj111ky@163.com

Mechanical Engineering Institute

Shandong University Jinan Shandong 250061 China CHINA 